
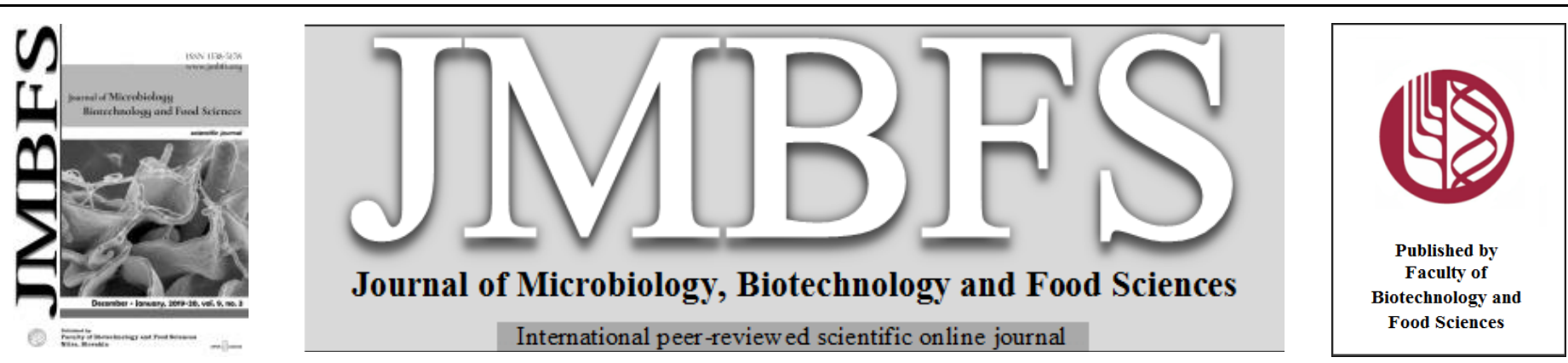

\title{
THE APPLICATION OF RESPONSE SURFACE METHODOLOGY FOR THE OPTIMIZATION OF AUTOCLAVE ASSISTED HCL HYDROLYSIS OF AN AGRO RESIDUE COCOA POD SHELLS FOR RELEASING REDUCED SUGARS
}

\author{
Vinayaka B. Shet ${ }^{* 1}$, Rakshith K. G. ${ }^{1}$, Nisha J. Shetty ${ }^{l}$,Vishwas C. Shetty ${ }^{l}$, Asha Siddik ${ }^{1}$,Louella Concepta Goveas ${ }^{l}$, C. Vaman Rao ${ }^{1}$, \\ Ujwal. P. ${ }^{l}$
}

\author{
Address(es): Mr.Vinayaka B. Shet, \\ ${ }^{1}$ NMAM Institute of technology (Affiliated to V.T.U, Belagavi), Department of Biotechnology Engineering, Nitte 574110,Udupi District, Karnataka, India, phone \\ number:+919448452511.
}

*Corresponding author: vinayakabshet@gmail.com, vinayakabshet@nitte.edu.in

doi: 10.15414/jmbfs.2019/20.9.3.548-551

\section{ARTICLE INFO}

Received 8. 3. 2018

Revised 31. 5. 2019

Accepted 4. 6. 2019

Published 1. 12. 2019

Regular article OPEN $\partial_{\text {AcCESS }}$

\begin{abstract}
Cocoa pod shells are the agro waste generated causing problem during the disposal. In the present study, possibility of utilizing the cocoa pod shells to release the reducing sugars has been explored. Hydrochloric acid hydrolysis assisted with autoclave was adopted to obtain reducing sugars. The one parameter at a time approach was implimented to screen the significant parameters influencing the hydrolysis among weight of cocoa pod shells, concentration of $\mathrm{HCl}$ and duration of autoclave. Parameters such as concentration of $\mathrm{HCl}$ and duration of autoclave were found to be significant. These parameters were chosen for the central composite design comprising of five levels using response surface methodology to optimize the hydrolysis process. At optimized condition of 54.15 minutes of autoclave treatment and $4.41 \%$ of $\mathrm{HCl}, 21.11 \mathrm{~g} / \mathrm{L}$ of maximum reducing sugar was released. A second order polynomial equation was generated having a good fit with $\mathrm{R}^{2}$ of 0.84 .
\end{abstract}

Keywords: Acid hydrolysis, Cocoa pod shell, Optimization, Reducing sugar

\section{INTRODUCTION}

The alarming issues related to the economic, social and environment has created an atmosphere of intensive research to substitute the raw materials for energy and chemical production in the coming years. Fossil fuel derived transportation fuels offer disadvantages such as pollution, greenhouse gas emission, unbalanced supply demand relations and resource depletion. This has created a necessity to explore for alternative energy sources such as, lignocellulosic biomass (Hamelinck et al., 2005). The demand for energy is steadily increasing due to an increase in population throughout the world. Currently non-renewable sources such as oil, coal and natural gas are used as the primary source of energy. It has been used for the production of electricity, fuel and other goods (Uihlein $\boldsymbol{e t}$ al., 2009). Lignocellulosic feedstock, dedicated energy crops, wood chips, sawdust, grasses, forestry residues and crop wastes are inexpensive and thus are available abundantly in nature. This does not compete with food, hence offers a promising source for biofuels in the next generations (Sarkar et al., 2012, Brethauer et al., 2015). The supply of potential global bioenergy is estimated in the range of less than 100 to over 400 EJ per year for 2050 (Berndes et al., 2003). Thus, naturally available biomasses on the earth are being explored to produce bioethanol. After petroleum, natural gas and coal biomass is found to be the fourth largest source of energy (Sheehan et al., 1999). Concentrated or dilute acid can be used for hydrolysis of hemicellulose and cellulose existing in the lignocellulosic residues into sugars (Wyman, 1994). Monosaccharide yield upto $90 \%$ can be attained by making use of concentrated acid pretreatment of residues since the acid pretreatment is much quicker in comparison with enzymatic hydrolysis (Heinonen et al., 2011). The annual generation of cocoa fruit in India is concerning 12,000 metric tonnes. Between 70 to $75 \%$ of entire weight of the fruit is represented by cocoa pod shell, i.e. 700 to $750 \mathrm{~kg}$ of residue is generated per each ton of cocoa fruit (Cruz et al., 2012).

Cocoa pod hydrolysate obtained using nitric acid, sulphuric acid and hydrochloric acid reported the presence of carbohydrates (Samah $\boldsymbol{e t}$ al., 2011) The neutralization step enables detoxification of hydrolysate making it favourable for the successive fermentation (Chandel et al., 2007).

In the current investigation, conversion of biomass for releasing reducing sugar using an agro residue cocoa pod shell (CPS) was explored. Due to the lack of availability of relevant literature on CPS hydrolysis, the design of experiments one parameter at a time (OPAT) approach was adopted for autoclave assisted hydrolysis by considering following parameters for screening such as, weight of CPS, time taken for hydrolysis and concentration of hydrochloric acid to identify the parameter level. The parameter at which maximum reducing sugar was released during OPAT studies were chosen as centre points for central composite design (CCD) to optimize the hydrolysis process.

\section{MATERIAL AND METHODS}

\section{Chemicals and raw material}

The chemicals used in the current investigation were procured from SigmaAldrich. Raw material cocoa pod shells were procured from a farmer of Peruvai village situated in Bantwal taluk, Karnataka, India.

\section{Processing of cocoa pod shell}

Cocoa pod shells were collected from Peruvai village of Dakshina Kannada, India. CPS was sun dried for 2 days and further placed in hot air oven (Borg scientific) at $90^{\circ} \mathrm{C}$ for overnight in order to remove $95 \%$ of the moisture. Size reduction unit operation was adopted and sieving was carried out using Taylor number 10 mesh to bring about uniformity in the particle size of $1.7 \mathrm{~mm}$. It was stored in the air tight container and placed in the refrigerator maintained at $4^{\circ} \mathrm{C}$ until further use.

\section{Optimization of Pre-Treatment Process}

\section{Screening of parameters}

OPAT method was adopted to screen the significance of the parameters. One parameter was varied by maintaining rest of the parameters at fixed value Parameters selected and its range for the OPAT experiments of autoclave assisted CPS hydrolysis is given in Table 1. All the OPAT experiments were performed in triplicate using Erlenmeyer flask containing $100 \mathrm{~mL}$ working volume and the resulting hydrolysate was neutralised to $\mathrm{pH} 7.0$ using sodium hydroxide. 3, 5Dinitrosalicylic acid (DNSA) method was implemented to determine the 
concentration of released reducing sugar (RRS) (Miller, 1959). As the parameters varied at one of its level, maximum sugars were released. The values of the parameters responsible for maximum RRS were maintained as centre point for CCD using response surface methodology (RSM).

Table 1 Parameters and its range chosen for the OPAT experiments of autoclave assisted CPS hydrolysis

\begin{tabular}{lcc}
\hline Parameter & Notation & Range \\
\hline Time $(\min )$ & $\mathrm{X}_{1}$ & $20-60$ \\
Concentration of $\mathrm{HCl}$ & $\mathrm{X}_{2}$ & $1-10$ \\
$(\% \mathrm{v} / \mathrm{v})$ & $\mathrm{X}_{3}$ & $4-20$ \\
Weight of CPS $(\% \mathrm{w} / \mathrm{v})$ & & \\
\hline
\end{tabular}

\section{Optimization of acid hydrolysis}

The two parameters viz. time $\left(\mathrm{X}_{1}\right)$ and concentration of acid $\left(\mathrm{X}_{2}\right)$ were optimized to obtain maximum sugar concentration using central composite design (CCD) with 12 runs.

Table 2 Coded parameters and its levels used in the central composite design.

\begin{tabular}{lcccccc} 
& & \multicolumn{5}{c}{ Levels } \\
\cline { 3 - 7 } Parameters & Notations & $\mathbf{- \alpha}$ & $\mathbf{- 1}$ & $\mathbf{0}$ & $\mathbf{+ 1}$ & $+\boldsymbol{\alpha}$ \\
\hline Time (min) & $\mathrm{X}_{1}$ & 25.85 & 30 & 40 & 50 & 54.15 \\
Concentration of & $\mathrm{X}_{2}$ & 0.17 & 1 & 3 & 5 & 5.83 \\
$\mathrm{HCl}(\% \mathrm{v} / \mathrm{v})$ & & & & &
\end{tabular}

$\underline{\text { Table } 3 \text { Central Composite Design for two parameters }}$

\begin{tabular}{lccc}
\hline Run No. & $\mathbf{X}_{\mathbf{1}}$ & $\mathbf{X}_{\mathbf{2}}$ & $\mathbf{Y}_{\mathbf{1}}$ \\
\hline 1 & 30.0 & 1.00 & 12.89 \\
2 & 30.0 & 5.00 & 19.52 \\
3 & 50.0 & 1.00 & 21.95 \\
4 & 50.0 & 5.00 & 23.29 \\
5 & 25.9 & 3.00 & 18.78 \\
6 & 54.2 & 3.00 & 23.11 \\
7 & 40.0 & 0.17 & 04.15 \\
8 & 40.0 & 5.83 & 19.87 \\
9 & 40.0 & 3.00 & 21.2 \\
10 & 40.0 & 3.00 & 20.94 \\
11 & 40.0 & 3.00 & 22.14 \\
12 & 40.0 & 3.00 & 20.94 \\
\hline
\end{tabular}

\section{Central composite design}

Time $\left(\mathrm{X}_{1}\right.$, minutes $)$ and concentration of $\mathrm{HCl}\left(\mathrm{X}_{2}, \% \mathrm{v} / \mathrm{v}\right)$ were the two experimental parameters screened for RSM optimization. OPAT studies revealed significant effect of these factors on the hydrolysis process. CCD was incorporated to obtain maximum RRS from the raw material. The concentration RRS during autoclave assisted hydrolysis was estimated as the response and denoted as "Y". Based on the two significant parameters, the CCD with five levels generated (Table 2) 12 experimental runs (Table 3 ) using trial version of statistica.

The analysis of variance (ANOVA) was carried for the experimental data obtained from CCD. The polynomial model with second order consisting linear and quadratic effect on the response was obtained

$Y=\beta o+\sum \beta i X i+\sum \beta i i X i^{2}+\sum_{i \neq j} \beta i j X i X j$

The response is denoted as "Y" and the polynomial coefficients as $\beta o, \beta i, \beta i i, \beta i j$. Independent parameters were represented as $X i, X j$.

The experiments were conducted to perform optimization of CPS acid hydrolysis in $250 \mathrm{ml}$ Erlenmeyer flask containing $100 \mathrm{~mL}$ acid solution

(Table 3). The weight of CPS (\%w/v) was maintained same for all the CCD experimental run.

\section{Estimation of RRS}

The following saccharides such as glucose, arabinose, xylulose, cellobiose, and galactose are expected to be the products of hydrolysis and reported to be reducing sugars (Brummer et al., 2014). Hence DNSA method was adopted to determine, the RRS concentration using UV Visible spectrophotometer (Systronics) at $540 \mathrm{~nm}$ (Miller, 1959).

\section{RESULTS AND DISCUSSION}

\section{Identifying the significant parameters based on OPAT}

Time duration of hydrolysis was varied from 20 to 60 minutes by maintaining rest of the parameters at fixed value $\left[\left(\mathrm{X}_{3}=4 \%(\mathrm{w} / \mathrm{v})\right.\right.$ and $\left.\mathrm{X}_{2}=4 \%(\mathrm{v} / \mathrm{v})\right]$. At 40 min of hydrolysis, a maximum of $18.2 \mathrm{mg} / \mathrm{mL}$ reducing sugar was released. Hence, 40 min $\left(\mathrm{X}_{1}\right)$ was chosen as a significant value (Fig.1). Weight of raw material CPS was increased from 4 to $20 \%(\mathrm{w} / \mathrm{v})$ by keeping other parameters fixed $\left[\left(X_{1}=40 \mathrm{~min}\right.\right.$ and $\left.\mathrm{X}_{2}=4 \%(\mathrm{v} / \mathrm{v})\right]$ (Fig.2). At $10 \% \mathrm{w} / \mathrm{v}$, maximum sugar of 37 $\mathrm{mg} / \mathrm{mL}$ was released. Beyond $10 \% \mathrm{w} / \mathrm{v}$ of CPS even though concentration increased, the volume of hydrolysate decreased. Concentration of $\mathrm{HCl}$ was varied from 1 to $10 \%(\mathrm{v} / \mathrm{v})$ by maintaining other parameters constant $\left(\mathrm{X}_{1}=40 \mathrm{~min}\right.$ and $\left.\mathrm{X}_{3}=10 \% \mathrm{w} / \mathrm{v}\right)$. At $3 \%(\mathrm{v} / \mathrm{v})$ acid maximum concentration of $38.54 \mathrm{mg} / \mathrm{mL}$ of reducing sugar was released (Fig.3). Beyond 3\% (v/v) of acid, released sugars were probably degraded slowly up to $9 \%(\mathrm{v} / \mathrm{v})$, hence the reduction of reducing sugar concentration was not significant. The increased reducing sugar concentration is due to the effect of hydrolysis and decreased sugar concentration is because of degradation of released sugars by the remaining $\mathrm{HCl}$ used in the hydrolysis. The parameter at which maximum RRS was obtained during OPAT studies were chosen as centre points for CCD.

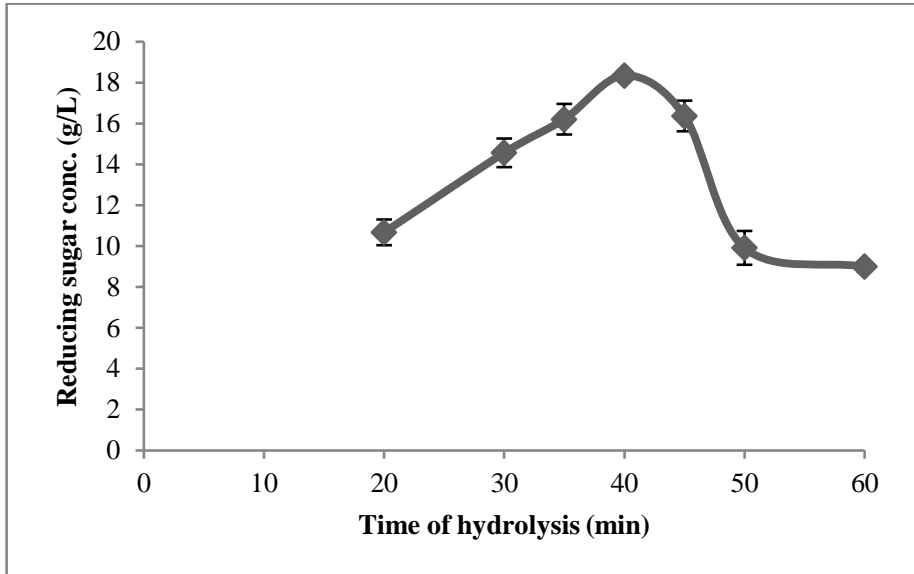

Figure 1- Effect of time of hydrolysis on the RRS

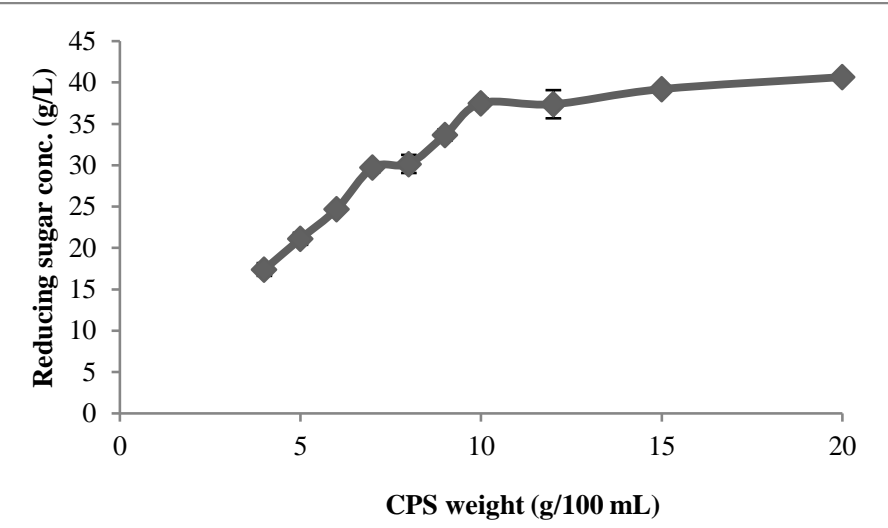

Figure 2- Effect of biomass weight on the RRS

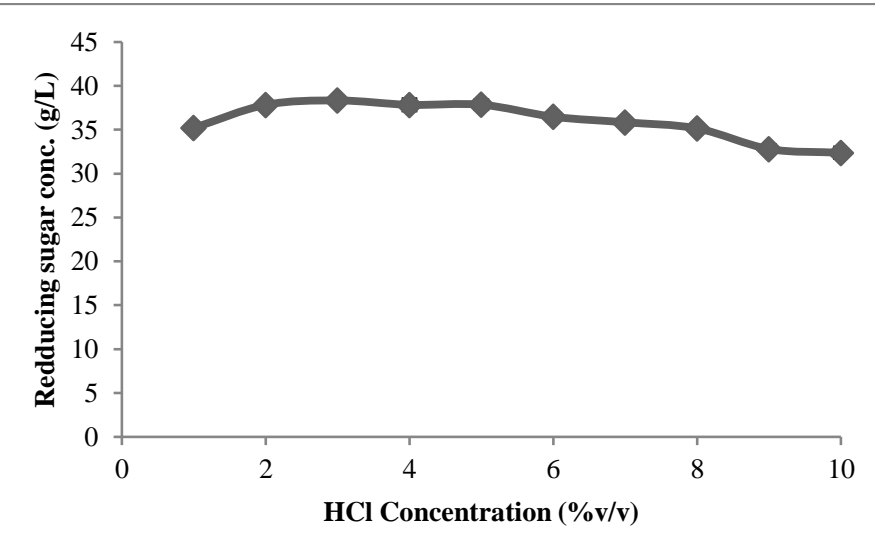

Figure 3- Effect of acid concentration on the RRS 


\section{Central composite design}

The effect of $\mathrm{X}_{1}$ (time) and $\mathrm{X}_{2}$ (concentration of acid) on RRS was obtained by CCD results (Table 3). Experimental values of RRS concentration obtained for the CCD is denoted as $\mathrm{Y}_{1}$

The regression equation for autoclave assisted acid hydrolysis process using two significant parameters and its linear and quadratic interactions to achieve RRS from CPS, is represented by following equation:

$$
\begin{gathered}
Y_{1}=-1.75898-0.00508 * \mathrm{X}_{1}+0.005504 * \mathrm{X}_{1}^{2}+10.40058 * \mathrm{X}_{2}- \\
0.97804 * \mathrm{X}_{2}^{2}-0.06612 \mathrm{X}_{1} * \mathrm{X}_{2}
\end{gathered}
$$

The values obtained from ANOVA for the RRS on $\mathrm{HCl}$ hydrolysis of CPS and the linear effects of the independent factors on RRS due to hydrolysis is represented in Table 4. The parameters having p-values less than 0.05 is considered as statistically significant (Guo et al., 2009).

Table 4 shows that the linear effect (L) of time and quadratic effect (Q) of $\mathrm{HCl}$ concentration was found to be statistically significant.

Table 4 ANOVA table for RRS on $\mathrm{HCl}$ hydrolysis of CPS

\begin{tabular}{lccccc}
\hline & SS & Df & MS & F & P-Value* $^{*}$ \\
\hline $\mathbf{X}_{\mathbf{1}}(\mathbf{L})$ & $\mathbf{4 4 . 8 9 5 7 7}$ & $\mathbf{1}$ & $\mathbf{4 4 . 8 9 5 7 7}$ & $\mathbf{5 . 4 8}$ & $\mathbf{0 . 0 5 7 8 1 5}$ \\
$\mathrm{X}_{1}(\mathrm{Q})$ & 1.941525 & 1 & 1.94152 & 0.24 & 0.643745 \\
$\mathbf{X}_{\mathbf{2}}(\mathbf{L})$ & $\mathbf{1 1 4 . 0 4 5 8}$ & $\mathbf{1}$ & $\mathbf{1 1 4 . 0 4 5 7 8}$ & $\mathbf{1 3 . 9 1}$ & $\mathbf{0 . 0 0 9 7 3 6}$ \\
$\mathbf{X}_{\mathbf{2}}(\mathbf{Q})$ & $\mathbf{9 8 . 1 0 5 6 2}$ & $\mathbf{1}$ & $\mathbf{9 8 . 1 0 5 6 2}$ & $\mathbf{1 1 . 9 7}$ & $\mathbf{0 . 0 1 3 4 7 4}$ \\
1L by 2L & 6.996025 & 1 & 6.99603 & 0.85 & 0.3912 \\
Error & 49.18021 & 6 & 8.19670 & & \\
Total SS & 325.1239 & 11 & & $\mathrm{R}^{2}=0.84873$ & \\
\hline
\end{tabular}

L: Linear, Q: Quadratic, $\mathrm{X}_{1}$ : Time, $\mathrm{X}_{2}$ : Concentration of $\mathrm{HCl}$

$* \mathrm{P}$ Values $<0.05$ indicate significance

The 3D surface plot for $\mathrm{Y}_{1}$ as a function of $\mathrm{X}_{1}$ (time) and $\mathrm{X}_{2}(\mathrm{HCl}$ concentration) is represented in Figure 4. It clearly shows that increase in concentration of RRS with increase in time of autoclaving. As the $\mathrm{HCl}$ concentration was increased, concentration of RRS increased continuously. The trend depicted in Fig. 4 of
RRS may be probably because of lignin removal with the increase in acid/alkali concentration (Sukri et al., 2014). The desirability plot was used to determine the optimized levels of significant parameters $X_{1}$ and $X_{2}$ for the maximum concentration of RRS by the hydrolysis (Fig.5). The optimized factor for maximum RRS (Y1) were $4.41 \%$ of $\mathrm{HCl}$ and 54.15 minutes of autoclave treatment with predicted RRS concentration of $25.14 \mathrm{~g} / \mathrm{L}$ as obtained from desirability plots. Validation experiment was conducted at optimized condition and RRS concentration was determined to be $21.11 \mathrm{~g} / \mathrm{L}$. Hydrolysis of CPS using $1.0 \mathrm{M}$ of $\mathrm{HCl}$ at $75^{\circ} \mathrm{C}$ for $4 \mathrm{~h}$ released the maximum glucose concentration of $30.7 \%$ w/v (Samah et al., 2011). Reducing sugar concentration of $4.9 \mathrm{~g} / \mathrm{L}$ was released from wheat straw (Saha et al., 2015). CPS hydrolysis using $\mathrm{H}_{2} \mathrm{SO}_{4}$ at 80 ${ }^{0} \mathrm{C}$ for $150 \mathrm{~min}$ of treatment released $45.08 \mathrm{mg} / \mathrm{ml}$ of reducing sugar (Awolu and Oyeyemi 2015). The $\mathrm{HCl}$ treated CPS at $75{ }^{\circ} \mathrm{C}$ for 4 hour released $135 \mathrm{~g} / \mathrm{L}$ of reducing sugar (Mbajiuka et al., 2015). The concentration of RRS from $8.36 \%$ w/v of CPS hydrolysis using $3.6 \mathrm{~N} \mathrm{HCl}$ in room temperature was found to be $4.09 \mathrm{~g} / \mathrm{L}$ (Shet et al., 2018).
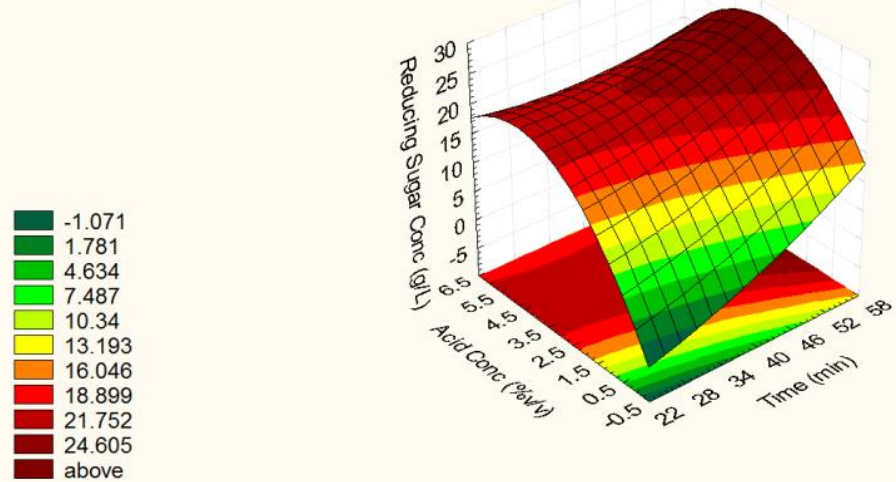

Figure 4- 3D surface plot exhibiting effect of time duration and acid concentration on hydrolysis of cocoa pod shell on RRS
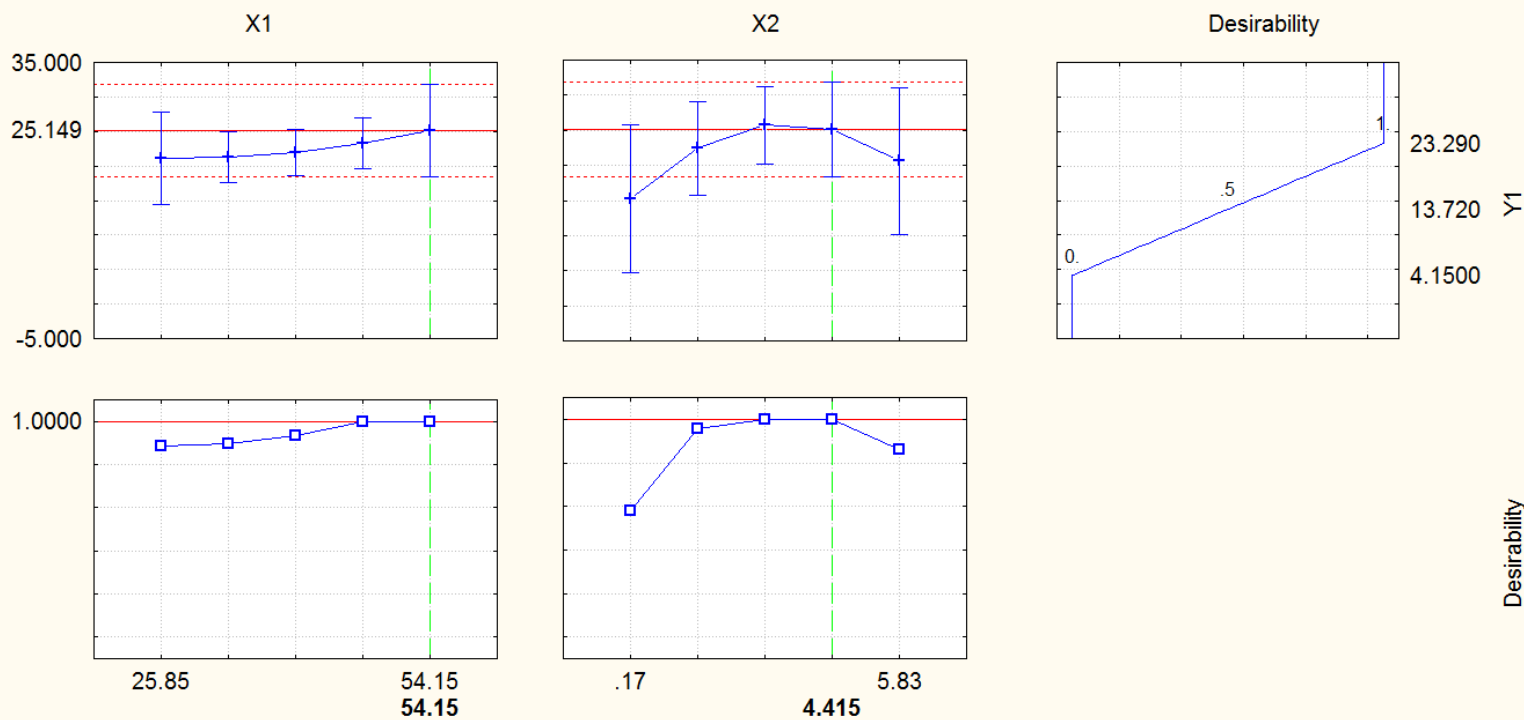

Figure 5- Desirability plot representing optimum parameters of hydrolysis process

\section{CONCLUSION}

In the current study, CPS hydrolysis was carried out using $\mathrm{HCl}$. A second order model was obtained for the hydrolysis and revealed the good fit of $\mathrm{R}^{2}$ with 0.84. Maximum RRS concentration of $21.11 \mathrm{~g} / \mathrm{L}$ at optimum conditions was achieved. The results are promising in terms of converting agro residue CPS into the reducing sugars; it could be used as precursor for the production of spectrum of biochemicals through fermentation. CPS is an environmentally and economically benign renewable source for the releasing reduced sugar since it is available abundantly in Bantwal taluk, Karnataka, India.

Acknowledgments: Authors would like to thank Mr. Anantha Ramakrishna of Peruvai village, Bantwal taluk, India for supplying of cocoa pod shells based on the necessity.

\section{REFERENCES}

Awolu, O., \& Oyeyemi, S. O. (2015). Optimization of Bioethanol production from Cocoa (Theobroma cacao) Bean Shell. Int. J. Curr. Microbiol. App. Sci, 4(4), 506-514.

Berndes, G., Hoogwijk, M., \& Broek, R. V. (2003). The contribution of biomass in the future global energy supply: a review of 17 studies. Biomass and Bioenergy,25(1), 1-28. http://dx.doi.org/10.1016/s0961-9534(02)00185-x

Brethauer, S., \& Studer, M. H. (2015). Biochemical Conversion Processes of Lignocellulosic Biomass to Fuels and Chemicals - A Review. CHIMIA International Journal for Chemistry,69(10), 572-581. http://dx.doi.org/10.2533/chimia.2015.572

Brummer, V., Jurena, T., Hlavacek, V., Omelkova, J., Bebar, L., Gabriel, P., \& Stehlik, P. (2014). Enzymatic hydrolysis of pretreated waste paper - Source of raw material for production of liquid biofuels. Bioresource Technology, 152, 543 547. http://dx.doi.org/10.1016/j.biortech.2013.11.030 
Chandel, A. K., Kapoor, R. K., Singh, A., \& Kuhad, R. C. (2007). Detoxification of sugarcane bagasse hydrolysate improves ethanol production by Candida shehatae NCIM 3501. Bioresource Technology,98(10), 1947-1950. http://dx.doi.org/10.1016/j.biortech.2006.07.047

Cruz, G. (2012). Production of Activated Carbon from Cocoa (Theobroma cacao) Pod Husk. Journal of Civil \& Environmental Engineering,02(02). http://dx.doi.org/10.4172/2165-784x.1000109

Guo, W., Ren, N., Wang, X., Xiang, W., Ding, J., You, Y., \& Liu, B. (2009) Optimization of culture conditions for hydrogen production by Ethanoligenens harbinense B49 using response surface methodology. Bioresource Technology,100(3), 1192-1196. http://dx.doi.org/10.1016/j.biortech.2008.07.070 Hamelinck, C. N., Hooijdonk, G. V., \& Faaij, A. P. (2005). Ethanol from lignocellulosic biomass: techno-economic performance in short-, middle- and long-term. Biomass and Bioenergy,28(4), 384-410. http://dx.doi.org/10.1016/j.biombioe.2004.09.002

Heinonen, J., Tamminen, A., Uusitalo, J., \& Sainio, T. (2011). Ethanol production from wood via concentrated acid hydrolysis, chromatographic separation, and fermentation. Journal of Chemical Technology \& Biotechnology,87(5), 689-696. http://dx.doi.org/10.1002/jctb.2766

Mbajiuka, C. S., Ifediora, A. C., Onwuakor, C. E., \& Nwokoji, L. I. (2015) Fermentation of Pods of Cocoa (Theobroma cacao L) Using Palm Wine Yeasts for the Production of Alcohol and Biomass. American Journal of Microbiological Research, 3(2), 80-84. http://dx.doi.org/10.12691/ajmr-3-2-7

Miller, G. L. (1959). Use of Dinitrosalicylic Acid Reagent for Determination of Reducing Sugar. Analytical Chemistry,31(3), 426-428 http://dx.doi.org/10.1021/ac60147a030

Samah, O. A., Sias, S., Hua, Y. G., \& Hussin, N. N. (2011). Production of Ethanol from Cocoa Pod Hydrolysate. ITB Journal of Sciences,43(2), 87-94. http://dx.doi.org/10.5614/itbj.sci.2011.43.2.2

Saha, B. C., Nichols, N. N., Qureshi, N., Kennedy, G. J., Iten, L. B., \& Cotta, M A. (2015). Pilot scale conversion of wheat straw to ethanol via simultaneous saccharification and fermentation. Bioresource Technology,175, 17-22. http://dx.doi.org/10.1016/j.biortech.2014.10.060

Sarkar, N., Ghosh, S. K., Bannerjee, S., \& Aikat, K. (2012). Bioethanol production from agricultural wastes: An overview. Renewable Energy,37(1), 19 27. http://dx.doi.org/10.1016/j.renene.2011.06.045

Sheehan, J., \& Himmel, M. (1999). Enzymes, Energy, and the Environment: A Strategic Perspective on the U.S. Department of Energy's Research and Development Activities for Bioethanol. Biotechnology Progress, 15(5), 817-827. http://dx.doi.org/10.1021/bp990110d

Shet, V. B., Bhat, M., Naik, M., Mascarenhas, L. N., Goveas, L. C., Rao, C. V.\& Aparna, A. (2018). Acid hydrolysis optimization of cocoa pod shell using response surface methodology approach toward ethanol production. Agriculture and Natural Resources, 52(6), 581-587.

http://dx.doi.org/10.1016/j.anres.2018.11.022

Sukri S.S.M., Rahman R.S., Illias R.M., Yaakob H. (2014). Optimization of alkaline pre-treatment conditions of oil palm fronds in improving the lignocelluloses contents for reducing sugar production, Romanian Biotechnol. Lett., 19(1), 9006 - 9018.

Uihlein, A., \& Schebek, L. (2009). Environmental impacts of a lignocellulose feedstock biorefinery system: An assessment. Biomass and Bioenergy,33(5), 793 802. http://dx.doi.org/10.1016/j.biombioe.2008.12.001

Wyman, C. E. (1994). Ethanol from lignocellulosic biomass: Technology,

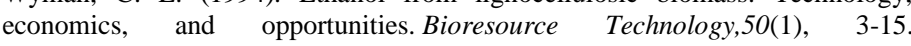
http://dx.doi.org/10.1016/0960-8524(94)90214-3 